\title{
Effects of the Elderly on Social Participation Activities and Hope
}

\author{
Gyeyoung Shin ${ }^{1}$, Mi-Jin Kim ${ }^{2}$ and Young-Soon $\mathrm{Choi}^{3}$ \\ ${ }^{1}$ College of Nursing, Shinhan University, 30 Beolmadeul-ro 40 beon-gil, Dongducheon, Gyeonggi-do, 11340, \\ Republic of Korea \\ ${ }^{2}$ College of Nursing, Shinhan University, 30 Beolmadeul-ro 40 beon-gil, Dongducheon, Gyeonggi-do, 11340, \\ Republic of Korea \\ ${ }^{3}$ Department of Nursing, Kangwon National University, Samcheck-si, Gangwon-do, 25949, Republic of Korea
}

Article History: Received:11 January 2021; Accepted: 27 February 2021; Published online: 5 April 2021

\begin{abstract}
- this study attempted to provide basic data on mental health by identifying factors that influence the personal characteristics of the elderly on social participation activities and hopes. Data collection conducted from October 1, 2019, to December 31, 2019, with the consent of the subjects, and a questionnaire used, and 144 participants used for the final analysis. The questionnaire was composed of demographic characteristics, social participation activities, and hope. The collected data were analyzed using descriptive statistics, t-test, ANOVA, Pearson's correlation, and multiple regression using SPSS 21.0 statistical program. Because of this study, differences in social participation activities according to general characteristics showed significant results in education, religion, cohabitation type, standard of living, and health concern. Hope showed significant differences in religion, marriage, cohabitation, monthly income, standard of living, housing, subjective health, and health concern. Social participation activities showed a positive correlation with hope, negative correlation with health concern, and hope had a negative correlation with subjective health status and health concern. In the results of the regression analysis, the factors influencing hope were in order of living standards and health concerns, and the factors used in the analysis showed $30.5 \%$ of the influencing factors.
\end{abstract}

Keywords-Social participation activities, Hope, Elderly, Quality of life

\section{INTRODUCTION}

In modern society, general living standards have improved due to the development of science, the improvement of national income by economic growth, and the improvement of living environment, with the development of medicine and the improvement of health and hygiene, the average life expectancy of the elderly is prolonging [1].

Elderly people are generally used to mean 'old people because they are very old,' but it is not easy to clearly distinguish the concept. The elderly are generally classified by age, the elderly welfare law in Korea stipulates that the age of 65, the national pension benefit, is called the elderly [2].

Scholars define the concept of the elderly in various ways. Bren defines the elderly as "peo ple who are physiological and physically declining, people whose mental functions and personalities are changing psychologically and those who lose their status and roles in social terms."([30], [35]-[37]).

According to the aging trend and outlook of the Korean society announced by the National Statistical Office, the ratio of aging to the total population is $12.9 \%$ in $2015,15.6 \%$ in $2020,19.9 \%$ in $2025,24.3 \%$ in $2030,32.5 \%$ in 2040 , and $38.2 \%$ in 2050 . Expected life expectancy of the elderly aged 65 years or older is 78.5 years for males and 85.1 years for females, and 1 out of 5 households are elderly households [3], and the proportion of the elderly is increasing.

Social activities are all forms of actions and thoughts that occur in the process of acquiring status, fulfilling roles, and forming social relationships as an individual grows in a group of families, neighbors, communities and national societies [4]

Social activity theory 1 which explains the relationship between the elderly's activities and life satisfaction, is based on the fact that as people age, social interaction decreases and their attitudes and behaviors change, the higher the degree of participation in private conversation activities, the higher the psychological satisfaction and life satisfaction of the elderly ([31], [38]-[41]).

The social activity of the elderly is an important factor in solving the psychological aspect of the elderly and increasing the satisfaction of old life. By supplementing the negative aspects of life that 
accompany the aging process and by compensating for loss of roles in the home and society, it can provide personal recognition of values and social ability, resulting in successful aging [5].

Social activities must have free time during the day [32]. Regardless of whether or not it is a social activity, it is given by individual needs in everyday life, and the activity experience and the state of mind are determined [33]. Social activities must be secured with time and conditions, while rest and balance with one's daily routine in order to escape the stress and stress of old age human relationships [10].

The elderly's participation in social activities argues that the elderly with high social participation are highly psychologically stable and have high life satisfaction [10]. The activation measures for the elderly in the aging society and aging society, the majority of the elderly want to participate than those who do not want to participate in social activities; many elderly people said that it is necessary to develop various programs to participate in social activities [34]

Looking at the difficulties experienced by the elderly aged 60 and over in the Social Research Report of the Statistical Office published in 2016, economic difficulties were the highest with $42.6 \%$, followed by health problems $37.2 \%$, no work distance $6.0 \%$, loneliness and alienation $3.8 \%$, unemployment or employment instability reported in $3.3 \%$ [3]. In order to resolve the difficulties of old age, that is, economic poverty, deterioration of physical function, and loss of health due to weakened health, loneliness and alienation, that active participation of the elderly is required. In addition to efforts by the government and local governments to solve the growing problem of the elderly, the attitude surrounding the elderly, that is, understanding the characteristics of the elderly in the community, as well as recognizing the importance of the elderly problem and desperately responding It is required [4].

Hope can to be said 'expectation for something you want, a desire that accompanies your expectations' [1]. People with high hopes can create clearly defined goals, and identify alternative routes to goals, so that alternative strategies can be implemented when currently used routes fail [1]. It can also overcome low levels of performance and test anxiety [7], and retain a more positive impact after failure than those with low hopes [8]. People who have high hope levels perceive life as having difficulties when they have difficulty in fulfilling their goals, while those with low hope perceive it as a disability that only happens to them [9]. In addition, people with high hope levels think about social support networks and ask them for help in stressful situations, but people with low hope levels do not think they have a social support network to help themselves and do not seek social support [10].

The main subjects of research on hope are cancer patients, critically ill patients, terminally ill patients, chronic rehabilitation patients, and elderly patients. In particular, the elderly need hope when they lose their duty and purposefulness [13]. Hope also activates the motivational system of interaction reactions; hope is a multi-dimensional vitality that believes to be personally important and uncertain, but a strong inner product that motivates individuals to overcome difficulties. As it has power, it is an important motivator for the elderly's life and affects survival, response to treatment, and qualitative life [12].

In a study of elderly people, the higher the self-esteem of the elderly, the higher the degree of hope [13], the spiritual well-being of the elderly related to hope, the spiritual well-being related to perceived health, and hope was related to perceived health [14].

As mentioned above, the elderly in Korean society experiencing an aging, aged, and ultra-aged society were very low at $25.6 \%$, who were satisfied with their lives [2]. Korean society, which entered into an aging society in 2020 , will soon experience an ultra-aged society, and predicted that various elderly problems will arise. Therefore, various methods should be developed to improve the quality of life of the elderly [2].

Therefore, this study aims to identify factors influencing social participation activities and life hopes according to the general characteristics of the elderly. In addition, this study conducted to identify detailed factors affecting the wishes of the elderly and to provide them as basic data for developing mental health education materials and nursing intervention programs to improve the quality of life for the elderly.

\section{RESEARCH METHOD}

\subsection{RESEARCH DESIGN}

This study is a descriptive research study using structured questionnaire to grasp the effect on social participation activities and life hopes of the elderly. 


\subsection{RESEARCH SUBJECT}

The subjects of this study conducted for the elderly in P-Gun, Gyeonggi-do, and G-City, Gangwon-do, which are multi-city cities. Convenience extracted as a person who understood the purpose of the study and voluntarily agreed to participate in the study. The number of samples was calculated for the multiple regression analysis using the $G *$ Power 3.1.5 program. The sample size was 138 when the significance level was .05 , the power was .95 , and the effect size was about .15 . In anticipation of dropouts, 160 copies were distributed, and 150 copies were recovered, but among them, 144 data, except 6 copies, were used for the final analysis.

\subsection{RESEARCH TOOLS}

2.3.1. SOCIAL PARTICIPATION ACTIVITIES: To measure the social participation activities of the elderly, the scale developed by Magen DJ and Perterson WA used by Choi Gyeong-in, and this scale modified and used by the researcher ([15],[16]). It is composed of 3 sub-areas with a total of 18 questions. The constituent factors: first, questions about the frequency and type of activities in social participation, second, positive attitudes toward social participation, and third, satisfaction with social participation. In this study, a 5-point scale of Likert was used, and 1 point (not at all), 2 points (not at all), 3 points (usually), 4 points (slightly yes), 5 points (very so) It is supposed to respond. In the study of Choi Kyung-in, the Cronbach's $\alpha$ value was .90, and the Cronbach's $\alpha$ value in this study was .901 .

2.3.2. HOPE: The elderly's hope scale consisted of the Trait Hope Scale and the State Hope Scale developed by Snyder and Harris [17]. Trait Hope Scale is a measure of hope through personal characteristics. The characteristic hope scale is composed of 12 questions, and each of the four questions is led, route, and neutral. The State Hope Scale is a tool to measure the right now's hope. The state hope scale consists of six questions, which consists of three questions, led and route questions.

In this study, Kang Yi-young developed the Korean version of the hope scale and used it [18]. In the lecture study, Likert was an 8-point scale. In this study, a 5-point scale of Likert was used, and 1 point (not at all), 2 points (not at all), 3 points (usually), 4 points (slightly yes), 5 points (very so) It is supposed to respond. Based on the theory of hope, as in the study of Kang Yi-young (2002), it was divided into characteristic hope scales and state hope scales and analyzed by each sub-factor. Neutral factors excluded from scoring.

In Kang's study, the Cronbach's $\alpha$ value was .87 , and in this study, the Cronbach's $\alpha$ value was .88 , showing adequate reliability.

\subsection{DATA COLLECTION}

Data collection conducted from October 1 to December 31, 2019, after obtaining approval for the survey from the person in charge of the institution. The 160 copies of questionnaires were distributed, and 150 copies collected. Of these, 144 copies were used for the final analysis, excluding 6 copies with unstable responses.

\subsection{DATA ANALYSIS}

The collected data analyzed using the SPSS 21.0 program. The details are as follows. The social participation activities and hope levels according to demographic and sociological characteristics analyzed by descriptive statistics, t-test, and ANOVA. Scheff'e test used for post-test. The correlation between social participation activities and hope analyzed by Pearson's correlation, and the effect on hope analyzed by multiple regression.

\section{RESEARCH RESULTS}

\subsection{DIFFERENCE IN SOCIAL PARTICIPATION ACTIVITIES AND HOPES ACCORDING TO THE CHARACTERISTICS OF THD SUBJECTS}

In the difference between social participation activities and hope according to the general characteristics, social participation activities include education $(\mathrm{F}=4.03 \mathrm{p}<.05)$, religion $(\mathrm{F}=32.79, \mathrm{p}<.001)$, and cohabitation type $(\mathrm{F}=10.00, \mathrm{p}<.001)$, living standards $(\mathrm{F}=3.19, \mathrm{p}<.001)$, and health concerns $(\mathrm{F}=9.39, \mathrm{p}<.001)$ showed statistically significant differences. Hope is religion $(\mathrm{F}=3.04, \mathrm{p}<.05)$, marriage form $(\mathrm{F}=6.59 \mathrm{p}<.001)$, cohabitation form $(\mathrm{F}=3.37, \mathrm{p}<.05)$, monthly income $(\mathrm{F}=2.56, \mathrm{p}<.05)$, Standard of living $(\mathrm{F}=7.59, \mathrm{p}<.001)$, 
Housing type $(\mathrm{F}=7.14, \mathrm{p}<.001)$, Subjective health status $(\mathrm{F}=3.20, \mathrm{p}<.05)$ Health concern $(\mathrm{F}=3.20, \mathrm{p}<.001)$ showed a statistically significant difference (Table 1).

Table 1. Difference in social participation activities and hopes according to the characteristics of the subjects. $(\mathrm{N}=144)$

\begin{tabular}{|c|c|c|c|c|c|c|c|}
\hline \multirow[b]{2}{*}{ Characteristic } & \multirow{2}{*}{\multicolumn{2}{|c|}{ Categories }} & \multirow[b]{2}{*}{$\mathrm{n}(\%)$} & \multicolumn{4}{|c|}{ social participation activil hope } \\
\hline & & & & $\mathrm{M} \pm \mathrm{SD}$ & $\begin{array}{l}\text { t/F }(p), \\
\text { Scheffe }\end{array}$ & $\mathrm{M} \pm \mathrm{SD}$ & $\begin{array}{l}\text { t/F }(p), \\
\text { Scheffe }\end{array}$ \\
\hline \multirow{2}{*}{ gender } & male & & $39(27.1)$ & $38.65 \pm 8.65$ & \multirow{2}{*}{$-.082(.935)$} & $35.85 \pm 9.27$ & \multirow{2}{*}{$.002(.998)$} \\
\hline & female & & $105(72.9)$ & $38.78 \pm 9.89$ & & $35.84 \pm 9.42$ & \\
\hline \multirow{3}{*}{ age(year) } & $65-69$ years & & $24(16.7)$ & $39.25 \pm 5.17$ & \multirow{3}{*}{$1.35(.262)$} & $35.41 \pm 8.20$ & \multirow{3}{*}{$1.42(.243)$} \\
\hline & 70-79 year & & $82(59.9)$ & $39.56 \pm 9.70$ & & $36.90 \pm 9.81$ & \\
\hline & $<80$ years & & $38(26.4)$ & $36.68 \pm 9.51$ & & $33.84 \pm 8.87$ & \\
\hline \multirow{4}{*}{$\begin{array}{l}\text { education } \\
\text { degree }\end{array}$} & no education & $\mathrm{a}$ & $32(22.2)$ & $34.50 \pm 10.37$ & \multirow{4}{*}{$\begin{array}{l}4.03(.009) \\
c>b>d>a\end{array}$} & $33.18 \pm 8.01$ & \multirow{4}{*}{$2.57(.056)$} \\
\hline & $\begin{array}{l}\text { elementary } \\
\text { school }\end{array}$ & $\mathrm{b}$ & $58(40.3)$ & $39.27 \pm 7.64$ & & $36.44 \pm 9.45$ & \\
\hline & middle schoc & $\mathrm{c}$ & $24(16.7)$ & $42.50 \pm 11.17$ & & $39.66 \pm 8.43$ & \\
\hline & $<$ high schoo & $\mathrm{d}$ & $30(20.8)$ & $39.26 \pm 6.76$ & & $34.46 \pm 10.39$ & \\
\hline \multirow{4}{*}{ religion } & no religion & $\mathrm{a}$ & $50(34.7)$ & $30.76 \pm 7.44$ & \multirow{4}{*}{$\begin{array}{l}32.79(<.001) \\
c>d>b>a\end{array}$} & $34.40 \pm 9.35$ & \multirow{4}{*}{$\begin{array}{l}3.04(.031) \\
c>d>b>a\end{array}$} \\
\hline & Christian & $\mathrm{b}$ & $62(43.1)$ & $42.51 \pm 7.11$ & & $35.51 \pm 9.62$ & \\
\hline & Catholic & $\mathrm{c}$ & $14(9.7)$ & $45.00 \pm 5.62$ & & $38.42 \pm 4.92$ & \\
\hline & Buddhism & $\mathrm{d}$ & $18(12.5)$ & $43.11 \pm 6.10$ & & $37.88 \pm 9.36$ & \\
\hline \multirow{4}{*}{ marital status } & single & $\mathrm{a}$ & $10(6.9)$ & $39.00 \pm 7.71$ & \multirow{4}{*}{ 2.064(.109) } & $29.40 \pm 9.85$ & \multirow{4}{*}{$\begin{array}{l}6.59(.000) \\
b>d>c>a\end{array}$} \\
\hline & spouse & $\mathrm{b}$ & $68(47.2)$ & $40.55 \pm 8.78$ & & $39.08 \pm 9.21$ & \\
\hline & bereavement & $\mathrm{c}$ & $56(38.9)$ & $36.53 \pm 10.88$ & & $33.85 \pm 7.56$ & \\
\hline & divorce & $\mathrm{d}$ & $10(6.9)$ & $38.60 \pm 11.48$ & & $31.40 \pm 11.80$ & \\
\hline \multirow{4}{*}{ cohabitation fo } & alone & $\mathrm{a}$ & $64(44.4)$ & $35.78 \pm 9.48$ & \multirow{4}{*}{$\begin{array}{l}10.00(<.001) \\
b>c>a\end{array}$} & $33.37 \pm 8.64$ & \multirow{4}{*}{$\begin{array}{l}3.37(.020) \\
b>c>a\end{array}$} \\
\hline & couple & $\mathrm{b}$ & $40(27.8)$ & $42.20 \pm 7.25$ & & $37.45 \pm 8.98$ & \\
\hline & children & $\mathrm{c}$ & $38(26.4)$ & $38.89 \pm 7.29$ & & $37.78 \pm 10.14$ & \\
\hline & other & $\mathrm{d}$ & $2(1.4)$ & $62.00 \pm .00$ & & $46.00 \pm .00$ & \\
\hline \multirow{2}{*}{ job } & no & & $110(76.4)$ & $37.56 \pm 8.99$ & \multirow{2}{*}{$-2.88(.004)$} & $35.36 \pm 9.86$ & \multirow{2}{*}{$-1.00(.266)$} \\
\hline & yes & & $34(23.6)$ & $42.58 \pm 8.41$ & & $37.41 \pm 7.35$ & \\
\hline \multirow{5}{*}{$\begin{array}{l}\text { monthly } \\
\text { income(won) }\end{array}$} & $>500,000 \mathrm{wo}$ & $\mathrm{a}$ & $76(53.8)$ & $38.97 \pm 8.78$ & \multirow{4}{*}{$.278(.025)$} & $34.15 \pm 9.12$ & \multirow{4}{*}{$\begin{array}{l}2.56(.041) \\
e>d>c>b<a\end{array}$} \\
\hline & $50-1,000,000$ & $\mathrm{~b}$ & $38(26.4)$ & $39.31 \pm 11.06$ & & $36.05 \pm 9.65$ & \\
\hline & $100-1,500,00$ & $\mathrm{c}$ & $16(11.1)$ & $37.00 \pm 8.40$ & & $38.00 \pm 7.78$ & \\
\hline & $<1,500,000$ & $\mathrm{~d}$ & $12(8.3)$ & $37.50 \pm 5.31$ & & $41.33 \pm 9.75$ & \\
\hline & other & $\mathrm{e}$ & $2(1.4)$ & $41.00 \pm .00$ & & $46.00 \pm .00$ & \\
\hline & very difficult & $\mathrm{a}$ & $12(8.3)$ & $32.66 \pm 11.03$ & & $35.16 \pm 7.63$ & \\
\hline & difficult & $\mathrm{b}$ & $66(45.8)$ & $39.39 \pm 8.20$ & $3.19(<.001)$ & $32.96 \pm 9.91$ & $7.59(<.001)$ \\
\hline Stantara OT & average & $\mathrm{c}$ & $58(40.3)$ & $39.96 \pm 8.79$ & $c>b>d>a$ & $37.72 \pm 7.94$ & $d>c>a>b$ \\
\hline & can afford & $\mathrm{d}$ & $8(5.6)$ & $33.75 \pm 11.52$ & & $47.00 \pm 4.31$ & \\
\hline housing type & self & $\mathrm{a}$ & $86(59.7)$ & $38.65 \pm 8.78$ & $.059(.943)$ & $39.02 \pm 8.78$ & 7.14(.001) \\
\hline
\end{tabular}




\begin{tabular}{|c|c|c|c|c|c|c|c|}
\hline & charter & $\mathrm{b}$ & $36(25.0)$ & $38.61 \pm 10.45$ & & $33.83 \pm 9.50$ & \multirow[t]{2}{*}{$a>b>c$} \\
\hline & monthly & $\mathrm{c}$ & $22(15.3)$ & $39.36 \pm 8.22$ & & $30.63 \pm 8.95$ & \\
\hline \multirow{4}{*}{$\begin{array}{l}\text { subjective heal } \\
\text { state }\end{array}$} & not very heal & $\mathrm{a}$ & $16(11.1)$ & $34.75 \pm 7.29$ & \multirow{4}{*}{$1.59(.192)$} & $31.50 \pm 10.02$ & \multirow{4}{*}{$\begin{array}{l}3.20(.025) \\
d>c>b>a\end{array}$} \\
\hline & not healthy & $\mathrm{b}$ & $64(44.4)$ & $38.71 \pm 9.75$ & & $34.75 \pm 9.80$ & \\
\hline & average & $\mathrm{c}$ & $54(38.0)$ & $40.22 \pm 8.63$ & & $37.44 \pm 8.27$ & \\
\hline & healthy & $\mathrm{d}$ & $10(6.9)$ & $37.40 \pm 8.68$ & & $41.20 \pm 7.52$ & \\
\hline \multirow{4}{*}{ health concern } & not concern & $\mathrm{a}$ & $2(1.4)$ & $41.00 \pm .00$ & \multirow{4}{*}{$\begin{array}{l}9.39(<.001) \\
b<a<c<d\end{array}$} & $44.00 \pm .00$ & \multirow{4}{*}{$\begin{array}{l}10.63(<.001) \\
b>a>c>d\end{array}$} \\
\hline & average & $\mathrm{b}$ & $14(9.7)$ & $48.00 \pm 7.76$ & & $45.28 \pm 2.52$ & \\
\hline & concern & $\mathrm{c}$ & $104(72.2)$ & $38.76 \pm 8.83$ & & $35.86 \pm 9.20$ & \\
\hline & very concern & $\mathrm{d}$ & $24(16.7)$ & $33.08 \pm 6.61$ & & $29.58 \pm 7.75$ & \\
\hline \multirow{2}{*}{$\begin{array}{l}\text { hospitalization } \\
\text { experience }\end{array}$} & no & & 116(80.6) & $38.58 \pm 9.31$ & \multirow{2}{*}{$-.439(.661)$} & $35.63 \pm 9.49$ & \multirow{2}{*}{$-.545(.586)$} \\
\hline & yes & & 28(19.4) & $69.42 \pm 8.21$ & & $36.71 \pm 9.96$ & \\
\hline
\end{tabular}

\subsection{SOCIAL PARTICIPATION AND HOPE THE LEVEL OF SUBJECT'S}

The social participation activities of the subjects were $38.75 \pm .75$ points out of 90 points, the conversion score of 100 points was 43 points, and the hope was $35.87 \pm .77$ points out of 55 points, and the conversion score of 100 points was 35 . Dot (Table 2 ).

Table 2. Level of social participation activities and hopes. $(\mathrm{N}=144)$

\begin{tabular}{|l|c|c|}
\hline \multicolumn{1}{|c|}{ Variable } & Range & M \pm SD \\
\hline social participation activity & $18 \sim 90$ & $38.75 \pm .75$ \\
\hline hope & $14 \sim 55$ & $35.84 \pm .77$ \\
\hline
\end{tabular}

\subsection{CORRELATION BETWEEN THE SUBJECT'S SOCIAL PARTICIPATION AND HOPE}

The social participation activities of the subjects showed a positive correlation with hope $(\mathrm{r}=.213, \mathrm{p}<.05)$, and a negative correlation with health concern $(\mathrm{r}=-.373, \mathrm{p}<.001)$. Hope showed positive correlation with subjective health status $(\mathrm{r}=.252, \mathrm{p}<.001)$ and negative correlation with health concern $(\mathrm{r}=-.416, \mathrm{p}<.001)$. Subjective health status was found to have a significant negative correlation with health concern $(r=-.261, p<.001)$ (Table 3$)$.

Table 3. Correlation between the subjects' social participation activities and hope $(\mathrm{N}=144)$

\begin{tabular}{|l|c|c|c|c|}
\hline Variable & $\begin{array}{r}\text { social participati } \\
\text { activities }\end{array}$ & hope & subjective health s & health concel \\
\hline social participation act & 1 & 1 & & \\
\hline hope & $.213^{*}$ & $.252^{* *}$ & 1 & \\
\hline subjective health status & .115 & $-.416^{* *}$ & $-.261^{* *}$ & 1 \\
\hline health concern & $-.373^{* *}$ & & & \\
\hline
\end{tabular}

$* p<.05, * * p<.001$

\subsection{FACTORS AFFECTING THE HOPE OF SUBJECT}

As a result of examining the values of tolerance and variance inflation factor (VIF) to determine whether multicollinearity occurs between each variable before conducting the regression analysis, the variance expansion 
factor value is .78 .86 all the furnaces were larger than 0.1 , and the dispersion expansion values were 1.15 to 1.28, which did not exceed 10, indicating that there was no problem of multicollinearity. Among the general characteristics of hope, marital status, cohabitation form, standard of living, subjective health status, health concern social participation activities, and a result of performing multiple regression analysis, as a factor influencing hope, living standards $(\beta=.284, \mathrm{p}<.001)$ and health concerns $(\beta=-.393, \mathrm{p}<.001)$ showed statistically significant results. In particular, health concerns analysed to have a negative effect on hope, and the explanatory power of hope of the factors used in the analysis was $30.5 \%$ (Table 4 ).

Table 4. Factors affecting the hope of subjects. $(\mathrm{N}=144)$

\begin{tabular}{|l|r|r|r|r|r|}
\hline Variable & $\mathbf{B}$ & $\mathbf{S E}$ & $\boldsymbol{\beta}$ & $\mathbf{t}$ & $\boldsymbol{p}$ \\
\hline (a constant) & 3.692 & .628 & & 5.877 & .000 \\
\hline marital status & -.071 & .072 & -.078 & -.996 & .321 \\
\hline cohabitation form & .101 & .061 & .130 & 1.646 & .102 \\
\hline standard of living & .262 & .071 & .284 & 3.705 & .000 \\
\hline subjective health status & .043 & .069 & .050 & .617 & .538 \\
\hline health concern & -.464 & .095 & -.393 & -4.878 & .000 \\
\hline social participation activities & -.003 & .105 & -.002 & -.030 & .976 \\
\hline & $\mathrm{Adj} \mathrm{R}^{2}=.2$ & $\mathrm{R}{ }^{2}=.30$ & $\mathrm{~F}=9.963$ & $P<.001$ & \\
\hline
\end{tabular}

\section{DISCUSS}

This study aims to identify factors influencing social participation activities and life hopes according to the general characteristics of the elderly. In addition, this study conducted to identify detailed factors affecting the wishes of the elderly and to provide them as basic data for developing mental health education materials and nursing intervention programs to improve the quality of life for the elderly.

According to the results of the study, the proportion of women was higher, with $27 \%$ for men and $73 \%$ for women. Result that shows the high proportion of women among the elderly in the gender composition of Korea.

The age range was $17 \%$ for $65-69$ years old, $60 \%$ for $70-79$ years old, and $26 \%$ for 80 years old. It seems that the study area high proportion of older seniors in rural areas.

The education degree was $22 \%$ non-school, $40 \%$ for primary school graduates, $17 \%$ for middle school graduates, and $21 \%$ for high school graduates. The ratio of high school graduates below $62 \%$ is high, indicating that an alternative to improve the health literacy of the elderly needed when developing an intervention program.

The cohabitation type is gradually decreasing in the proportion of households living alone (44\% 4), households living with spouses $(28 \%)$, and households living with children (26\%). This result is similar to the study in the ratio of single-family households (33.4\%), spouse and cohabitation households (32.7\%), and households living with children (15.3\%) [18].

As family relations change along with industrialization and urbanization, over the past 30 years, the household type of the elderly population over the age of 65 has changed significantly, and as the number of married couple's increases, the number of elderly living alone after the spouse's death expected to increase. However, rapid family relations and changes in the caregiving structure of the elderly can negatively affect the health and quality of life of the elderly, so attention is required [18].

There were $24 \%$ of cases with jobs, $76 \%$ of cases with no jobs, $80 \%$ of cases with monthly income of less than 1 million won, and 54\% of people with less than normal living standards. It has been shown that the economy suffers from a decrease in income. Has been shown that economic difficulties caused by a decrease in income due to the absence of jobs. The elderly's participation in economic activities makes social satisfaction and personal achievement, as well as life satisfaction as a means of livelihood for the elderly who are experiencing economic poverty. As such, the elderly's economic activities not only satisfy the basic needs of earning a living, but can also treat the sense of loss that comes from lack of a job role; social participation is the most influential 
factor in improving the quality of life in old age by improving the physical and psychological satisfaction of the elderly [19].

The perception of subjective health status was 55\% that is not healthy, and $7 \%$ that was healthy showed many differences. As for the health concern, $11 \%$ of 'no concern' and $89 \%$ of 'concern', and many elderly people have a negative evaluation of their health, and thus it seems to have a high interest in health.

The elderly in old ages are at risk of deteriorating quality of life as they undergo social and psychological changes due to retirement, economic instability, changes in their roles in society and the home, and death of their spouse, as well as physical changes such as deterioration or loss of physical function and illness [25]. In addition, in order to maintain optimal health and functional status, efforts to maintain health by themselves, that is, practice of health behaviors are required [21], and the more desirable health behaviors are reported, the higher the health level and the health-related quality of life are reported. ([21],[22]).

The social participation activity of the elderly was $38.75 \pm .75$ based on 90 points, which was rather low at 43 points with a 100-point conversion score. Social participation activities according to general characteristics showed statistically significant differences in education, and it found that middle and high school graduates had more social participation than the uneducated elderly did. In religion, the elderly with religions such as Christianity, Catholicism, and Buddhism scored higher in social participation than those without religion, and showed statistically significant results. In the cohabitation form, the elderly living with a couple or their children scored higher in social participation activities than the elderly living alone, and showed statistically significant results. As for the standard of living, the elderly with a average standard of living had higher scores in social participation than the elderly with a difficult standard of living, and showed statistically significant results. In health concerns, the elderly who had no concern in health had higher social participation activity scores than the elderly who were concern in health, and showed statistically significant differences.

Havighurst's theory of activity maintains a psychologically and physically healthy life for older people with higher participation in social activities, and social dismissal theory is that social retirement loses its previous role, lacks self-confidence, and it is that the social adaptation ability reduced by feeling the crisis of identity [23].

Changes or loss of social relations experienced in old age are known to negatively affect the health-related quality of life of the elderly ([21]-[24]), it was shown that active social participation activities have an important and positive effect on the psychological and physical well-being of the elderly [25]. The elderly living alone feel more psychosocial isolation than the elderly living together, and are known to have poor quality of life due to lack of social support ([21]-[24]).

Therefore, social support needed to re-evaluate the ability of the elderly, and it is necessary to lead a healthy elderly live by resolving various problems that can occur in old age through continuous education to have a positive awareness of the elderly [23].

The index of hope for the elderly was $35.87 \pm .77$ points out of 55 points, and the conversion score of 100 points was low at 35 points. The hope according to the general characteristics was higher for the elderly with religion than for the elderly without religion, and showed statistically significant results. Religious activities are social-level functions that give the elderly, so that they can join the elderly in all age groups in a comprehensive way, and provide opportunities for contact with various societies; it reduces the sense of alienation and allows one to have a sense of self-esteem with a sense of belonging [26]. Therefore, the religious activities of the elderly have a great influence on the improvement of life satisfaction in old age by positively accepting their lives and can be a variable of successful aging [27].

In the case of marriage, the elderly who had a spouse had higher hope scores than the elderly who were single or divorced, and showed statistically significant results. In the cohabitation form, the elderly living together with a couple or children had higher hope scores than the elderly living alone, and showed statistically significant results. The higher the monthly income, the higher the hope score for the elderly and showed statistically significant results. In the standard of living, the elderly with economic affords had higher hope scores than those without affords, and showed statistically significant results. In the case of a housing type, the elderly with selfhouse had higher hope scores than that of the elderly who charter or monthly, and showed statistically significant results. Even in the subjective health condition, the elderly who answered that they were healthy had higher hope scores than those who said they were not healthy, and showed statistically significant results. In health concerns, the elderly who were not concern in health had higher hope scores than the elderly who were concern in health, and showed statistically significant results.

Hope is a force that encourages a person to move forward, which is related to toughness and processes reality beyond what is visible [32]. An energy can not only recreate human life in pain but also maintain and restore health [27], and is an essential element of the human life process. In most cases, however, it is difficult to have an expectation that the future will be better because old age is perceived as the end point of life, and the hope level of the elderly is often low [29].

The social participation activities of the subjects found to have a positive correlation with hope, and negative correlations with health concerns. The higher the social participation activity, the higher the hope index and it is necessary to expand the social participation activity program to improve hope, which is an indicator of the 
quality of life of the elderly. Hope found to have a positive correlation with subjective health status and negative correlation with health concern. Elderly hope index higher found to determine their health status is also positive.

As a factor influencing hope, living standards and health concerns showed statistically significant results. The explanatory power of hope of the factors used in the analysis was 30.5\%. Decreasing social participation activities and declining hope can cause psychological and psychological health problems for individuals, so continuous research and efforts needed on how to improve social participation activities and hopes of the elderly.

\section{CONCULUSION}

This study conducted to identify factors affecting social participation activities and life hopes of the elderly, and to provide them as basic data for developing educational materials and nursing intervention programs to improve mental health of the elderly.

Based on the study results to the following suggestions such.

First, it is necessary to study and focus on factors affecting the hopes of the elderly.

Second, follow-up studies on the relationship between social participation activities and hope of the elderly needed and continuous studies on social participation activities needed.

Third, research and interest in the development and application of intervention programs needed to improve the hope of life for the elderly.

\section{REFERENCES}

\section{JOURNAL ARTICLE}

[1] Kim SR. "Differences in mental health of the elderly according to religious experiences activities." Master's Thesis, University of Han Seo, Korea, 2013, pp.69.

[2] Bibhu Santosh Behera \& Bibhuti Prasad Mohapatra, "A Gender Comparative Socio-Economic Study With Respect to Social Participation, Membership Status and Outward Orientation among the Farmers and Farmwomen in Keonjhar District of Odisha", International Journal of Environment, Ecology,Family and Urban Studies (IJEEFUS), Vol. 6, Issue 3, pp, 91-102

[3] Nam BH. "The effects of the personal characteristics of the elderly on the quality of their life with recovery resilience and social engagement as mediating effects." PhD's Thesis, Seoul Hanyoung University, Korea, 2017, pp.165.

[4] Darsana S. \& Aswathy Chandrakumar, "Participation of Members in Developmental Activities of Nabard Farmers' Clubs in Kerala State", International Journal of Agricultural Science and Research (IJASR) ISSN (P): 2250-0057; Vol. 7, Issue 6, pp, 59-66

[5] Statistics Korea, Future Population Estimation Results, 2016.

[6] Hoi Wing Chan, "Participating in Extra-Curricular Activities and Fostering Greater Learner Autonomy Among Highly Proficient Secondary Students in Hong Kong", International Journal of Educational Science and Research (IJESR), Vol. 8, Issue 2, pp, 33-40

[7] Kwon SJ. "The effects of social activity on the successful aging of the senior," Master's Thesis, DaeJeon University, Korea, 2013, pp.85.

[8] G.Swarupa Rani \& M.Sarada Devi, "Perceptions of Retired Professionals Towards Participation in Post-Retirement Activities", International Journal of Applied and Natural Sciences (IJANS), Vol. 6, Issue 5, pp; 111-116

[9] Lee MH. "(A) study on the relationships between social activities and life satisfaction of the aged people in Busan metropolitan city." Master's Thesis, Dong-A University, Korea, 2003, pp.85.

[10] Shraddha Kulkarni, "Inclusion of Corporate Social Responsibility Practices as a Part of Curriculum @ Indira School of Business Studies, India and its Impact Over the Awareness \& Sense of Responsibility of Students towards Community", International Journal of Business and General Management (IJBGM), Vol. 6, Issue 3, pp ; 1-18

[11] Nam KM., Nam HH. "The influence of older people's satisfaction factors of housing environment on their quality of life: focusing on the mediating effect of self-esteem and depression." Korean Journal of Social Welfare Studies. 4.3 (2013):.395-420. 
[12] Indrajit Brahma, "The Growth of the Bodo Social Organisation and its Participation for the Development of the Society”, IMPACT: International Journal of Research in Humanities, Arts and Literature (IMPACT: IJRHAL), Vol. 4, Issue 8, Aug 2016, 41-46

[13] Snyder, CR. "Hope theory: Rainbows in the mind.” Psychological inquiry. 13.4 (2002): 249-275.

[14] Snyder CR., Shorey HS., Cheavens J., Pulvers KM., Adams III VH., and Wiklund C. "Hope and academic success in college.” Journal of educational psychology. 94.4 (2002): 820.

[15] Snyder CR., LaPointe AB., Jeffrey Crowson J., and Early S. "Preferences of high-and low-hope people for self-referential input.” Cognition \& Emotion. 12.6 (1998):.807-823.

[16] Yano, K., Reed, D. M., and McGee, D. L. "Ten-year incidence of coronary heart disease in the Honolulu Heart Program: relationship to biologic and lifestyle characteristics." American journal of epidemiology. 19.5 (1984): 653-666.

[17] Ebright PR and Lyon B. "Understanding hope and factors that enhance hope in with breast cancer." Oncol Nurs Forum Apr. 29.3 (2002): 561-568.

[18]Beck, AT., Weissman, A., Lester, D. and Trexler, L. "The measurement of pessimism: The hopelessness scale.” Journal of Consulting and Clinical Psychiatry. 20 (1974): 779-785.

[19] Kim SH. "Relationship between Self-Esteem and Hope of the Elderly." Master's Thesis, Chonbuk University, Korea, 2000, pp.72.

[20] Sung MS. "A correlation study on spiritual well-being, hope and perceived health status of the elderly.” Master's Thesis, Keimyung University, Korea, 1988, pp.66.

[21] Choi GI. "A study on the social participation of the elderly; focused on Wonju." Master's Thesis, Sangji University, Korea, 2008, pp.74.

[22] Snyder, CR., Harris, C., Anderson, JR., Holleran, SA., Irving, LM., Sigmon, ST., Yoshinobu, L., Gibb, J., Langelle, C., and Harney, P. "The will and the ways: development and validation of an individual-differences measure of hope." Journal of Personality and Social Psychology. 60.4 (1991): 570-585.

[23] Kang LY. "Development and application of counselling process hope scales." PhD's Thesis, Sungkyunkwan University, Korea, 2002, pp156..

[24] Kim YB., and Lee SH. "Effects of the elderly's health statuses, health behavior, and social relations on their health-related quality of life: focusing on family types." J Korean Acad Community Health Nurs. 29.3 (2018): 310-321.

[25] Yoon SD., and Han GH, "Productive activities and psychological well-being of the rural elderly in Korea." Journal of the Korea Gerontological Society. 24.2 (2004): 57-77.

[26] Kim JY, Lee SG, and Lee SK., "The relationship between health behaviors, health status, activities of daily living and health-related quality of life in the elderly." Journal of the Korean Gerontological Society. 30.2 (2010): 471-484.

[27] Kim KS. "Effects of the health status and health behavior on health-related quality of life of the elderly living alone and living with their families: Using data from the 2014 community health survey." Journal of Korean Academy Community Health Nursing. 28.1 (2017): 78-87.

[28] Moon SM. "Gender differences in the impact of socioeconomic, health-related, and health behavioral factors on the health-related quality of life of the Korean elderly." Journal of Digital Convergence. 15.6 (2017): 259-271.

[29] Kim MR. "Effects of the motivation and the satisfaction of participation in the lifelong education for the elderly on their life satisfaction." Master's Thesis, University of Han Seo, Korea, 2013.

[30] Suh SR., Kim MH. "Influencing factors on the health-related quality of life of older adults living alone.” Journal of the Korean Gerontological Society. 34.4 (2014): 705-716.

[31] Park KS.. Park YR, Yum YS. "The effects of social participation on health related quality of life among rural elderly.” Mental Health \& Social Work. 43.2 (2015): 200-227.

[32] Lee YG. "A study on life satisfaction of the elderly; Focused on participation in religious and social activities." Master's Thesis, Cheongju University, Korea, 1994. 
[33] Kim HY. "Analysis of Differences in Life Satisfaction according to the Types of Leisure Activities of the Elderly-Daegu Metropolitan City, Suseong-gu." Master's Thesis, Yeungnam University, Korea, 2006, pp.82.

[34] Kim DS., Moon WH., Ahn SY., Oh HS., Kwon KH., and Park MK. "Meta-analysis of the research findings concerning functional relationships of explanatory variables to hope." Journal of Korean Academy of Nursing. 34.5 (2004): 673-684.

[35] Park YJ., Kim JO. "The effects of tai chi exercise on hope, dependency, and perceived health status of elderly women.” J Muscle Jt Health. 21.2 (2014): 106-113.

\section{BOOK}

[1] Bren, LB. “The aging individual, In C. Tibits (Ed.) Handbook of Social Gerontology." University of Chicago press, Chicago, 1960, pp.150-157.

[2] Havighurst, RJ. "Disengagement and Patterns of Aging," The University of Chicago Press, 1968.

[3] Murhy, JF. “Concepts of Leisure: Philosophical. Implication.” Prentice Hal, 1974.

[4] Neulinger, John. “To Leisure: An Introduction.” Boston : Alynand Bacon, 1981

[5] Havighurst RJ. "Developmental task and education (3rded.).” NY: David Mckay, 1972.

\section{CONFERENCE PROCEEDINGS}

[6] Kim MJ., Choi YS. "The Effect of the Personal Characteristics of the Elderly on Social Participation Activities and Hope.” Journal of Nursing Methodology (NADIA), 2020, 1(1): pp. 17-24.

[7] AeDuck In. "Social Practice Program for Elderly Residents of Jeju Island, South Korea, Affected by Historic " 4.3 " Trauma: Short-term application of psychosocial model of trauma." International Journal on Consulting Psychology for Patients. GVPress. 1.11 (2017): 31-38. http://dx.doi.org/10.21742/IJCPP.2017.1.1.05

[8] Won-Mi Jung, Youn-Sik Hong. “A Design and Implementation of a Smart Bed for Elderly Patients." International Journal of Elderly Welfare Promotion and Management. GVPress. 1. 1 (2017): 1-6. http://dx.doi.org/10.21742/IJEWPM.2017.1.1.01

[9] Chang-Hwan Bae, Jung-Ho Lee. "Comparison of Muscle Activities around the Shoulders of Patients with Frozen Shoulder According to the Scapular Stabilization Exercise Method." International Journal of Elderly Welfare Promotion and Management. GVPress. 1. 1. (2017): 7-12. http://dx.doi.org/10.21742/IJEWPM.2017.1.1.02

[10] Haemi Jee, Chang-Hwan Kim, Jaehyun Park. "Gender Comparisons of Visuospatial Neglect in Neurodegenerative Disorder Patients via e-Pen based Cognitive Assessment System." International Journal of Elderly Welfare Promotion and Management. GVPress. 1. 1 (2017): 13-20. http://dx.doi.org/10.21742/IJEWPM.2017.1.1.03

[11] Sun-Jung Park, Young -Hui Hwang. "Death Awareness and Death Preparation Experiences In Hospitalized Elderly People in a Long-Term Care Facility.” International Journal of Elderly Welfare $\begin{array}{lllllll}\text { Promotion and } & \text { Management. }\end{array}$ http://dx.doi.org/10.21742/IJEWPM.2017.1.1.04

[12] Myung-Kyu Yi, Hee-Joung Hwang. "A New Lifelog Management Scheme for Intelligent Healthcare Service." International Journal of Elderly Welfare Promotion and Management. GVPress. 1. 1 (2017): 29-36. http://dx.doi.org/10.21742/IJEWPM.2017.1.1.05 